\title{
Educação de qualidade e gestão pública: a construção do planejamento de uma secretaria de educação
}

\author{
Quality education and public management: the building of an educational \\ secreteriat
}

Calidad educativa y gestión pública: una construcción de la educación una

secretaría

DIRLÉIA FANFA SARMENTO
JARDELINO MENEGAT
VERA LÚCIA RAMIREZ

Resumo: O texto analisa o processo do planejamento de uma Secretaria Municipal de Educação tendo como protagonistas os profissionais que atuam nessa Secretaria. Os achados (decorrentes da análise do conteúdo de documentos, de observações no Diário de Campo e entrevistas) sinalizam para: o sentimento de pertença, o empoderamento e o protagonismo dos sujeitos envolvidos; a reflexão sobre a própria práxis; a (re)construção de conceitos e a revisão de concepções por meio da investigação-ação-formação; relações interpessoais facilitando o processo comunicacional e o fluxo das informações; o comportamento pró ativo na busca pela resolução de problemas; a consolidação de uma gestão focada em resultados e a qualificação dos serviços prestados.

Palavras-chave: : Educação de qualidade - Excelência em Gestão PúblicaPlanejamento estratégico.

Abstract: This text analyses the process of planning of a Municipal Board of Education, having the professionals who perform in that board as the protagonists. The conclusions reached (resulting from the analysis of documents, of observations in field journals and interviews) signalize to the sense of belonging, empowerment, and prominence of the subjects involved. Other results were the reflection on the own praxis; the reconstruction of concepts and the revision of conceptions through the research-action-formation; interpersonal relationships facilitating the communicative process and the flow of information; the proactive behavior searching for troubleshooting; the consolidation of a management focused on results and the qualification of the services performed.

Keywords: Quality Education - Excellence in Public Management - Strategic Planning.

Resumen: El artículo analiza el proceso de planificación de una Educación Municipal teniendo como actores profesionales que trabajan en este Secretaria. Os hallazgos (resultantes del análisis del contenido de los documentos, observaciones en el diario de campo y entrevistas) de la señal: un sentido de pertenencia, el empoderamiento y el rol de los involucrados; a reflexionar 
sobre su propia práctica; (re) construcción de conceptos y la revisión de los conceptos a través de la investigación-acción-formación; proceso de comunicación interpersonal y facilitar el flujo de información; comportamiento proactivo en la búsqueda de la resolución de problemas; la consolidación de una gestión centrada en los resultados y la calificación de los servicios prestados.

Palabras clave: calidad de la educación - excelencia en publicaciones de planificación estratégica de gestión

\section{INTRODUÇÃO}

A gestão estratégica tem-se constituído em elemento fundamental para a concretização da Missão, da Visão e dos Objetivos de qualquer instituição, não sendo mais possível administrar com base numa conduta de "tentativa e erro" e/ou pautada exclusivamente por experiências prévias. De acordo com Drucker (2009, p.27):

Qualquer organização existente [...] decai rapidamente se não inovar. Inversamente, qualquer organização nova [...] fracassa se não administrar. Não inovar é a única e a maior razão para o declínio das organizações existentes. Não saber administrar é a única e maior razão para o fracasso de novos empreendimentos. (grifo do autor).

No que se refere à gestão das instituições públicas (MADEIRA, 2008), a preocupação com um gerenciamento estratégico culminou com a aprovação do Decreto $n^{\circ}$ 5.378, de 23 de fevereiro de 2005 (BRASIL, 2005a) que instituiu o Programa Nacional de Gestão Pública e Desburocratização (GESPÚBLICA) e o Comitê Gestor do Programa Nacional de Gestão Pública e Desburocratização. Compreendido como uma política pública, tal Programa é decorrente de ações governamentais no âmbito federal com vistas à promoção de uma gestão pública de excelência, visando a contribuir para a qualidade dos serviços públicos prestados aos cidadãos.

Revitalizado com base no exposto na Carta de Brasília (BRASIL, 2008) e, posteriormente, em 2014, pela Secretaria de Gestão Pública (SEGEP), do Ministério do Planejamento, Orçamento e Gestão, o GESPÚBLICA está pautado nos princípios constitucionais da Legalidade (estrita observação ao que estabelece a Lei); da impessoalidade (não fazer acepção de pessoas); da moralidade (pautar a gestão por um código moral); da publicidade (gestão pautada pela transparência); e da eficiência (observar relação entre qualidade do serviço e qualidade do gasto). É considerado um programa que observa as características e especificidades das instituições públicas, estando alinhado ao pensamento contemporâneo sobre excelência em gestão, passível de aplicação a toda a administração pública, em todos os poderes e esferas do governo. 
O Modelo de Excelência em Gestão Pública (MEGP) é uma referência a ser seguida por qualquer instituição pública e tem como sustentação os seguintes fundamentos: excelência dirigida ao cidadão; gestão participativa; gestão baseada em processos e informações; valorização das pessoas; visão de futuro; aprendizado organizacional; agilidade; foco em resultados; inovação e controle social. Está constituído por "sete partes integradas, que orientam a adoção de práticas de excelência em gestão com a finalidade de levar as organizações públicas brasileiras a padrões elevados de desempenho e de excelência em gestão" (BRASIL, 2006, p. 7). As sete partes estão organizadas em quatro blocos: Liderança; Estratégias; Planos; Cidadãos e Sociedade (primeiro bloco); Pessoas e Processos (segundo bloco), Resultados (terceiro bloco), e Informação e Conhecimento (quarto bloco).

No MEGP parte-se do pressuposto de que "por meio da liderança forte da alta administração, que focaliza as necessidades dos cidadãos destinatários da ação da organização, os serviços/produtos e os processos são planejados conforme os recursos disponíveis, para atender esse conjunto de necessidades". (Idem). Por isso, o primeiro bloco, Liderança, Estratégias e Planos, e Cidadãos e Sociedade é denominado planejamento. As Pessoas e os Processos, segundo bloco, representam a execução do planejamento, viabilizando e concretizando as ações que transformam objetivos e metas em resultados. Isto é: "são as pessoas, capacitadas e motivadas, que operam esses processos e fazem com que cada um deles produza os resultados esperados" (Idem). Os Resultados, terceiro bloco,

Representam o controle, pois, serve para acompanhar o atendimento à satisfação dos destinatários dos serviços da ação do Estado, o orçamento e as finanças, a gestão das pessoas, a gestão de suprimentos e das parcerias institucionais, bem como o desempenho dos serviços/produtos e dos processos organizacionais (Idem).

A Informação e Conhecimento, quarto bloco, representa a "inteligência da organização". Assim, nesse bloco,

São processados e avaliados os dados e os fatos da organização (internos) e aqueles provenientes do ambiente (externos), que não estão sob seu controle direto, mas, de alguma forma, podem influenciar o seu desempenho. Esse bloco dá à organização a capacidade de corrigir ou melhorar suas práticas de gestão e, consequentemente, seu desempenho. (BRASIL, 2006, p. 7).

Uma gestão estratégica requer uma postura estratégica por parte dos integrantes de uma organização (especialmente das lideranças que estão à frente de postos gerenciais) e porisso, pressupõe a existência de um planejamento (estratégico, tático e operacional) que viabilize o desdobramento das estratégias no cotidiano 
da organização. No entender de Libâneo (2001, p. 149): “sem planejamento, a gestão corre ao sabor das circunstâncias, as ações são improvisadas, os resultados não são avaliados". O planejamento estratégico tem por base a construção proativa do planejamento (PAGNONCELLI; VASCONCELLOS FILHO, 2001; OLIVEIRA, 2013), considerando os ambientes interno e externos com vistas à consecução dos objetivos da organização, equacionando seus objetivos e otimizando seus recursos às oportunidades identificadas (KOTLER, 1998). Dentre as principais contribuições do planejamento estratégico, destacam-se: possibilitar um olhar sistêmico sobre a organização; oportunizar a reestruturação organizacional mediante as mudanças ambientais; auxiliar na constituição da identidade organizacional, direcionando seus integrantes para a consecução dos objetivos; viabilizar a celeridade nas tomadas de decisão e das ações decorrentes; buscar a otimização dos recursos organizacionais; possibilitar o monitoramento e avaliação sistemática dos indicadores estabelecidos (PAGNONCELLI; VASCONCELLOS FILHO, 2001; KOTLER, 1998; OLIVEIRA, 2013).

Considerando que o planejamento estratégico focaliza o delineamento e monitoramento de indicadores oriundos dos objetivos estratégicos decorrentes da Missão, Visão e Princípios de uma determinada organização, os principais envolvidos em sua construção são, geralmente, os gestores dos níveis hierárquicos mais altos. Afinal, são esses gestores os que possuem o poder de tomada de decisão sobre os rumos organizacionais. Ao refletir sobre o planejamento estratégico em organizações governamentais, Andrade (2012, p. 118) destaca a necessidade de se ter presente as dimensões políticas e ideológicas presentes em cada gestão, pois elas interferem na tomada de decisões. Assim, "os processos de planejamento desenvolvidos nas organizações governamentais necessitam estar "afinados" com as prioridades definidas pelos governantes”. (ANDRADE, 2012, p. 118, grifo do autor).

Nesse sentido, ao aplicar os princípios da excelência em gestão pública, tendo-se como foco a construção do planejamento estratégico de uma Secretaria Municipal de Educação, um dos principais resultados que se espera alcançar é a consolidação de uma cultura organizacional pautada na gestão estratégica, que contribua para a celeridade dos processos e práticas administrativas e pedagógicas para uma educação de qualidade.

Para Andrade (2012, p. 54), a cultura organizacional é “o conjunto de valores, crenças, atitudes e normas compartilhadas que moldam o comportamento e as expectativas de cada membro da organização". O autor continua, explicando que "pode ser conceituada como a maneira de ser da organização, o que resulta do conjunto da maneira de ser de seus membros" (Ibidem).

Compreendendo a Secretaria Municipal de Educação como um polo 
dinamizador das políticas públicas educacionais e de seus possíveis modos de normatização e efetivação por meio de dispositivos legais e ações específicas dentro de um município, seu modelo de gestão pode constituir-se num facilitador ou num entrave para a democratização da gestão da escola pública e a consolidação de uma educação de qualidade nas escolas que estão sob sua responsabilidade. Dito de outro modo, é da Secretaria Municipal de Educação que saem as normativas e demais procedimentos administrativos e pedagógicos a serem observados pelos gestores de cada escola, de forma a se efetivar o que preconizam os dispositivos legais nacionais. Ainda, esta Secretaria é que responde pela gestão dos recursos direcionados à educação oriundos do governo federal e do orçamento municipal. Também é ela que organiza a distribuição dos profissionais que irão atuar em cada contexto educacional. Desse ponto de vista, depreende-se que a gestão da escola (PARO, 2003) está intimamente interligada aos modos de organização e de gestão de uma Secretaria de Educação. Portanto, conforme destacado anteriormente, os modos de funcionamento dessa instância podem interferir nas formas de funcionamento da escola. No âmbito de um município, a Secretaria Municipal de Educação é uma das instâncias que deve zelar pela educação pública de qualidade.

Uma educação de qualidade persegue o desenvolvimento das potencialidades de cada pessoa, respeitando suas características e necessidades e vislumbra a formação de pessoas capazes de atuar de forma ética, crítica, participativa e responsável no contexto em que vivem, pautando seus modos de ser e agir pelo bem-estar comum. Para que isso se concretize, são necessários, dentre outros aspectos: a) infraestrutura (espaços físicos, equipamentos e demais materiais necessários) da escola compatível com as necessidades e especificidades dos níveis de ensino que oferta; b) formação continuada para que os professores se atualizem constantemente e se qualifiquem para o exercício da função docente, tendo presentes as demandas sociais emergentes e as tendências educacionais na contemporaneidade; c) interação entre família e escola, oportunizando-se diferentes espaços e tempos para a participação, especialmente dos responsáveis pelo estudante, buscando-se a corresponsabilidade nos processos educativos; d) estabelecimento de parcerias e redes de cooperação entre a escola e instituições públicas e privadas, que possam contribuir para que os estudantes (principalmente aqueles em situação de vulnerabilidade social) permaneçam na escola e tenham êxito na aprendizagem.

Feitas tais considerações, este artigo tem como objetivo analisar o processo constituivo do planejamento estratégico da Diretoria Administrativa de uma Secretaria Municipal de Educação (SME) situada no Estado do Rio Grande do Sul (Brasil), enfatizando as contribuições da pesquisa-ação colaborativa nesse processo, enquanto postura que alimenta o compromisso político, o pensamento 
crítico e as relações cooperativas para a constituição de comunidades de aprendizagem. Neste texto, partimos das seguintes questões norteadoras: quais as contribuições de uma gestão estratégica para o aprimoramento dos processos e práticas no âmbito de uma Secretaria de Educação? O planejamento estratégico pode ser construído a partir da perspectiva da pesquisa-ação colaborativa? Quais pressupostos teóricos devem fundamentar esse tipo de ação prática? Quais os ganhos possíveis dos participantes de uma pesquisa-ação colaborativa na construção do planejamento estratégico? Nossa intenção consiste em argumentar em prol da importância e da finalidade de uma gestão estratégica para as instituições educativas públicas, explicitando as contribuições desta para o aprimoramento e consolidação de uma educação de qualidade.

No intuito de discorrer sobre as questões apresentadas, introduzimos a temática investigativa com pressupostos da gestão estratégica, salientando a função e a relevância do planejamento estratégico como ferramenta que pode contribuir para a excelência na gestão pública. A seguir, contextualizamos a proposta da pesquisa-ação colaborativa por meio de um exercício meta-analítico, identificando o campo, o horizonte teórico e o enfoque espistemológico a partir do qual estruturamos a referida investigação. $\mathrm{Na}$ sequência, apresentamos reflexões oriundas da interpretação e análise dos dados sobre o processo de construção do planejamento estratégico, refletindo sobre os avanços, os desafios e as lacunas encontradas no decorrer da investigação. Por fim, tecemos algumas considerações finais evidenciando os principais achados do estudo e sinalizamos algumas questões para a continuidade do projeto de pesquisa-ação colaborativa no âmbito da Secretaria Municipal de Educação.

\section{A PESQUISA-AÇÃO COLABORATIVA ENQUANTO POSTURA METODOLÓGICA E POLÍTICA}

Para Carr e Kemmis (1988), a pesquisa-ação colaborativa se fundamenta no princípio da investigação-ação crítica. Nela, o investigador opta por uma posição que articula teoria e prática, de forma crítica, num processo de açãoinvestigação. Quando o pesquisador faz uma opção teórico-metodológica não o faz de modo imune, neutro e descolado de suas concepções. Ele carrega consigo suas crenças, valores, concepções e posicionamentos. No dizer de Miranda e Resende (2006, p.514):

Tratar-se-ia, assim, de uma pesquisa que articula a relação entre teoria e prática no processo mesmo de construção do conhecimento, ou seja, a dimensão da prática que é constitutiva da educação - seria fonte, lugar privilegiado da pesquisa. Além disso, a própria investigação se converteria em ação, em intervenção social, possibilitando ao pesquisador uma atuação efetiva sobre a realidade estudada. 
Reflexão e prática, ação e pensamento, polos antes contrapostos, agora seriam acolhidos em uma modalidade de pesquisa que considera a intervenção social na prática como seu princípio e seu fim último.

Franco (2005, p. 485-486), apresenta três dimensões que comumente mobilizam os pesquisadores a optar pela pesquisa-ação:

a) Quando a busca de transformação é solicitada pelo grupo de referência à equipe de pesquisadores, a pesquisa tem sido conceituada como pesquisa-ação colaborativa, em que a função do pesquisador será a de fazer parte e cientificizar um processo de mudança anteriormente desencadeado pelos sujeitos do grupo; b) se essa transformação é percebida como necessária a partir dos trabalhos iniciais do pesquisador com o grupo, decorrente de um processo que valoriza a construção cognitiva da experiência, sustentada por reflexão crítica coletiva, com vistas à emancipação dos sujeitos e das condições que o coletivo considera opressivas, essa pesquisa vai assumindo o caráter de criticidade e, então, tem se utilizado a conceituação de pesquisa-ação crítica; c) se, ao contrário, a transformação é previamente planejada, sem a participação dos sujeitos, e apenas o pesquisador acompanhará os efeitos e avaliará os resultados de sua aplicação, essa pesquisa perde o qualificativo de pesquisa-ação crítica, podendo ser denominada de pesquisa-ação estratégica.

No caso do estudo em pauta, é possível destacar, de forma articulada, as duas primeiras dimensões apresentadas pelo autor como propulsoras da pesquisa. Corroborando sua posição, entendemos que:

Se alguém opta por trabalhar com pesquisa-ação, por certo tem a convicção de que a pesquisa e ação podem e devem caminhar juntas quando se pretende a transformação da prática. No entanto, a direção, o sentido e a intencionalidade dessa transformação serão o eixo da caracterização da abordagem da pesquisa ação (FRANCO, 2005, p. 485).

O cerne da pesquisa-ação está no fato de que não basta apenas compreender, mas é preciso, a partir dessa compreensão, contribuir para a transformação tanto dos sujeitos quanto de suas realidades e contextos. Dessa forma, o foco na construção do planejamento estratégico tem como objetivo contribuir para que os profissionais da educação que atuam na SME potencializem suas competências gestoras instrumentalizando-se para o exercício de uma gestão pública participativa e transparente e, consequentemente para a melhoria dos serviços públicos prestados à comunidade educativa.

\section{Contexto do locus investigativo}

O locus investigativo é a Secretaria Municipal de Educação de uma cidade situada na Região Metropolitana de Porto Alegre. Essa Secretaria prima por uma 
educação de qualidade compreendida como um direito de todos, fomentando a inovação e a excelência nos processos educativos, tendo em vista o desenvolvimento e a aprendizagem dos educandos.

Para o exercício das atribuições que lhe competem, torna-se fundamental a consolidação de uma gestão estratégica tendo em vista a efetivação das metas estabelecidas no Plano de Governo Municipal para o período entre 2013-2016 e os dispositivos nacionais que versam sobre a educação de qualidade. Para tanto, partimos do princípio de que os profissionais que atuam nessa Secretaria necessitam ampliar um conjunto de competências gestoras que os habilitem a ser protagonistas de ações que contribuam para a excelência em gestão pública na área educacional, solidificá-las e dar-lhes continuidade. Vale salientar que tais profissionais possuem sua formação inicial na área da educação, mas nem sempre possuem conhecimentos específicos de gestão estratégica e de suas ferramentas respectivas.

Iniciamos o estudo em julho de 2013, tendo como protagonistas os profissionais da educação que atuam na Secretaria Municipal de Educação e integram as seguintes Unidades da Diretoria de Administração: a) Administrativa; b) De Expediente; c) De Matrículas e Frequência; d) de Programas, Sistemas e Políticas Federais; e e) De Alimentação e Merenda Escolar.

A gestão participativa e transparente é o mote do ideário políticopedagógico do governo municipal. Esse ideário tem contribuído para a discussão e a construção coletiva de dispositivos orientadores da ação educativa no âmbito da rede pública e sua articulação com a Universidade. Essa estratégia tem-se constituído um diferencial para ambas as instituições, considerando-se que a pesquisa, ao propiciar a análise reflexiva e a construção e socialização do conhecimento, contribrui, também, para repensar a educação no munícipio.

\section{Instrumentos de coleta de dados e etapas constituintes da abordagem metodológica}

No decorrer da pesquisa, foram utilizados para a coleta de dados: a análise documental (LAVILLE; DIONNE, 1999; PIMENTEL, 2001; GIL, 2010; PÁDUA, 2011); o questionário (LAVILLE ; DIONNE, 1999 ; MARCONI : LAKATOS, 2006); os registros de observação dos encontros formativos, realizados no Diário de Campo (BOGDAN; BIKLEN, 1994) e a entrevista semiestruturada (MAY, 2004). Adotamos. para a análise dos dados, a Técnica de Análise de Conteúdo proposta por Bardin (1988). Para o autor, a análise de conteúdo configura-se como um conjunto de técnicas que possibilitam, por meio de procedimentos sistemáticos de descrição do conteúdo, a realização de inferências 
acerca da produção e/ou recepção de determinada mensagem (BARDIN, 1988). Em relação ao processo da análise de conteúdo, Bardin apresenta três etapas: a) pré-análise; b) exploração do material; c) tratamento dos resultados, inferência e interpretação.

Tendo presente as peculiaridades da abordagem metodológica adotada nesta pesquisa (KEMMIS; MCTAGGART, 1992), as etapas constituintes do processo foram: Diagnóstico-reconhecimento e fortalecimento de identidade de grupo ( $1^{a}$ etapa); Planejamento das ações ( $2^{a}$ etapa); Aplicação de estratégias de ação, processo de observação-registro e avaliação ( $3^{a}$ etapa); e Reflexão e reorganização (4 etapa). Na seção a seguir, são apresentados e analisados os dados coletados em cada uma dessas etapas, tendo em vista a construção do planejamento estratégico da SME.

\section{O PROCESSO CONSTITUTIVO DO PLANEJAMENTO ESTRATÉGICO: DESAFIOS, AVANÇOS E LACUNAS}

Com base no exposto na seção anterior, são apresentados e analisados, na sequência, os dados coletados em cada uma das etapas constituintes da abordagem metodológica da pesquisa-ação colaborativa. Importante retomar que esta abordagem metodológica serviu de eixo orientador para o processo investigativo da construção do planejamento estratégico da Diretoria de Administração da SME.

\section{$1^{a}$ Etapa: Diagnóstico-reconhecimento e fortalecimento de identidade de grupo}

O trabalho com o coletivo de participantes do estudo é um dos aspectos fundamentais da pesquisa-ação. Dessa forma, ações são postas em prática para viabilizar o processo de pesquisa diagnóstica que compõe essa primeira etapa. Para tanto, aplicamos um questionário a fim de caracterizar os participantes, identificar as suas concepções sobre o modelo de gestão da Secretaria Municipal de Educação, o ambiente de trabalho, o suporte organizacional e as possíveis dificuldades encontradas no exercício da função, além de colher sugestões para o aprimoramento das práticas cotidianas.

Participaram do processo de construção do planejamento estratégico um gestor de cada uma das unidades vinculadas à Diretoria de Administração (Unidade de Alimentação; Unidade Administrativa; Unidade de Matrícula e Frequência; Unidade de Programas, Sistemas e Políticas Federais e Unidade de Expediente), totalizando cinco gestores. 
A faixa etária dos gestores é de 29 a 50 anos, sendo que três são do gênero feminino e dois do masculino. Dos cinco gestores, dois realizaram curso de especialização na área de gestão e os demais são graduados em Pedagogia, Matemática e Educação Física. $O$ tempo de atuação desses gestores como servidores públicos varia de seis meses a 25 anos e, na função atual, de 2 meses a 4 anos. É importante salientar que esses gestores foram os responsáveis por mobilizar a participação dos colaboradores sob sua gestão no processo de construção do planejamento estratégico de sua unidade.

Em relação ao modelo de gestão adotado pela SME, os gestores consideram que há uma intencionalidade e esforço para consolidar uma gestão democrática e participativa. Destacam, entretanto, que existem alguns entraves que, por vezes, dificultam a efetivação desse ideário. Dentre tais entraves, são citados pelos gestores: a atitude individualista de alguns profissionais, que atuam na SME; alguns relacionamentos interpessoais que parecem dar sustentabilidade a determinadas relações de poder, que, em muitos casos, priorizam os interesses de determinados grupos em detrimento da coletividade; ruídos no processo de comunicação entre os colaboradores de alguns setores; o perfil de alguns profissionais nem sempre compatível com as demandas requeridas para o exercício de determinada função.

É fundamental que os gestores tenham conhecimento do perfil de seus colaboradores e a compatibilidade ou não destes com o perfil dos cargos que ocupam e das funções que devem realizar. É possível inferir que o êxito e a satisfação dos colaboradores no ambiente de trabalho estão relacionados com a possibilidade de cada um de poder desempenhar ações compatíveis com suas habilidades e competências. Conforme destaca Drucker (2009, p.29):

\begin{abstract}
A administração trata dos seres humanos. Sua tarefa é capacitar as pessoas a funcionar em conjunto, efetivar suas forças e tornar irrelevantes suas fraquezas. É disso que trata uma organização, e esta é a razão pela qual a administração é um fator crítico e determinante. Hoje em dia, praticamente todos nós somos empregados por instituições administradas, grandes ou pequenas, empresariais ou não. Dependemos da administração para nossa sobrevivência. E a nossa capacidade de contribuição à sociedade também depende tanto da administração das organizações em que trabalhamos quanto dos nossos próprios talentos, dedicação e esforço.
\end{abstract}

Portanto, o gestor precisa ter habilidades gerenciais, sendo a liderança fundamental para a ação gestora. $\mathrm{O}$ ser humano sofre influências do ambiente em que se encontra inserido. Normalmente onde reina autoritarismo, com regras severas, a tendência é a de que os comportamentos sejam passivos, pois as pessoas querem evitar repreensões. Também o clima organizacional tem efeito direto e impactante sobre a satisfação e o rendimento dos membros de uma organização. Um 
clima organizacional que instiga a pessoa a se expandir e a se desenvolver contribui, de forma positiva, para o desenvolvimento de atitudes proativas e a criatividade.

Dentre as sugestões apresentadas pelos gestores de cada unidade que integra a Diretoria de Administração, destacam-se a necessidade da melhoria da infraestrutura (espaços e equipamentos), de forma que seja possível atender às demandas emergentes, aprimorando-se, cada vez mais, a qualidade dos serviços já prestados; melhor articulação entre o administrativo e o pedagógico para a tomada de decisões, fortalecendo-se a trajetória construída; continuidade da valorização e do reconhecimento dos servidores; readequação dos colaboradores e de seus respectivos perfis profissionais a suas áreas de atuação. Importante é destacar que a ênfase na necessidade de uma melhor articulação entre as dimensões administrativa e pedagógica remete à reflexão de que qualquer tomada de decisão no âmbito administrativo traz implicações para o pedagógico e vice-versa, pois todo investimento em educação depende da disponibilidade de recursos financeiros para subsidiá-lo.

\section{$2^{a}$ Etapa: Planejamento das ações}

A proposição de espaços formativos ganha centralidade nesta segunda etapa. Essa abordagem é circunscrita pela visão de que a educação é um processo amplo de formação e de humanização. Sendo assim, consideramos a formação como parte essencial do processo investigativo (FRANCO, 2005; PIMENTA, 2005; MONCEAU, 2005; ZEICHNER, DINIZ-PEREIRA, 2005; ELLIOT, 2000). A pesquisa-ação pode agregar valor no processo de formação, sem ser, no entanto, reduzida a ela, pois possibilita a intervenção e a transformação da realidade por parte dos envolvidos. A ação teórica emerge enquanto processo social, humano e humanizador, através do qual podemos compreender melhor a nós mesmos e ao mundo no qual vivemos.

Sob esse viés, "o fato de teorizar forma parte do processo dialético de autotransformação e de mudança social: o processo através do qual os indivíduos reconstroem a si mesmos e, ao mesmo tempo, reconstroem sua vida social" (CARR, 1996, p.15). Dessa forma, no decorrer da pesquisa, foram realizados encontros formativos com os protagonistas de nosso estudo, cujos focos temáticos foram detectados durante a realização da primeira etapa da pesquisa. Assim, num movimento dialético e dialógico, trabalhamos na perspectiva de formação com os profissisonais da Diretoria de Administração, tendo em vista o empoderamento como gestores e a constituição como partícipes de um projeto coletivo. De acordo com Murad (2008, p.195): 
O gestor forma sua equipe, acompanha-a e confia nela, delega responsabilidades e divide tarefas. Ele socializa as informações necessárias para que todos os colaboradores compreendam a organização e sintam-se parte dela. Cria uma cultura do empoderamento, na qual cada pessoa torna-se responsável pela sua área de atuação e, efetivamente, age de forma autônoma e independente. (grifo do autor).

Nessa etapa foram realizados oito encontros, com periodiciade semanal e duração de três horas cada, totalizando 24h. Nos encontros formativos 1 e 2, foram retomados os pontos centrais a ser considerados no planejamento estratégico, constantes nos dispositivos legais vigentes relativos à Educação Básica, tais como a Lei de Diretrizes e Bases da Educação Nacional (LDBN) $\mathrm{n}^{\circ}$ 9.394, de 20 de dezembro de 1996 (BRASIL, 1996) e o Plano Nacional de Educação 2001-2010 - Lei no 10.172, de 09 de janeiro de 2001 (BRASIL, 2001), dentre outros.

A seguir, nos encontros formativos 3,4 e 5 foram trabalhados os pressupostos constantes do GESPÚBLICA acerca da excelência em gestão pública e nos encontros 6,7 e 8 os pressupostos teórico-metodológicos do planejamento estratégico.

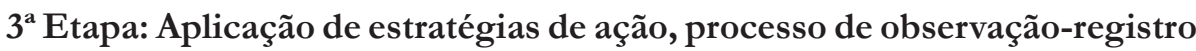 e avaliação}

Nessa etapa ocorreu a construção do planejamento estratégico, para o que foram realizados encontros formativos com os gestores e também trabalhos dirigidos realizados por esses gestores com os colaboradores sob sua responsabilidade. No total, foram nove encontros, totalizando 27 horas, não estando contabilizadas nesse conjunto as horas utilizadas pelos gestores para a construção coletiva, com seus respectivos colaboradores, por meio do trabalho dirigido. A construção do planejamento estratégico observou os seguintes passos, estruturados a partir do que sugerem autores como Mülller (2014); Hitt e Hoskinon (2002); Certo, Marcondes e Cesar (2010) e Tavares (2010).

\section{Passo 1 - Reflexão sobre a Identidade Organizacional}

Ao falar em organização, temos presente a definição apresentada por Chiavenato (1989, p.3):

As organizações são unidades sociais (e, portanto, constituidas de pessoas que trabalham juntas) que existem para alcançar determinados objetivos. Os objetivos podem ser o lucro, as transações comerciais, o ensino, a prestação de serviços públicos, a caridade, o lazer etc. Nossas vidas estão intimamente ligadas às organizações, porque tudo o que fazemos é feito dentro das organizações. 
Dessa forma, a identidade organizacional se refere à visão geral de uma determinada organização. Trata-se, pois, do foco de seu negócio (área de atuação); da Missão (sua razão de existir, seu compromisso e dever), da Visão (objetivos a serem atingidos seja a curto, médio ou longo prazo) e dos Princípios/ Valores (crenças guias para o comportamento e a tomada de decisões visando ao cumprimento da Missão e à concretização da Visão). (MÜLLLER, 2014; HITT; HOSKINON, 2002; CERTO, MARCONDES, CESAR, 2010 e TAVARES, 2010). Assim, o foco dos Encontros formativos nove, dez e onze foi: análise do foco de atuação, da Missão, da Visão e dos Princípios/Valores da SME. Após tais análises e reflexões, foram construídas a Missão, a Visão e os Princípios/Valores da Diretoria de Administração e suas respectivas Unidades.

\section{Passo 2 - Análise Ambiental}

$\mathrm{Na}$ continuidade da construção do planejamento estratégico, o grupo de gestores debruçou-se sobre a realização da análise ambiental, também chamada diagnóstico estratégico. Para esta análise, foram destinados três encontros (Encontros formativos 12,13 e 14). A análise ambiental consiste na identificação dos fatores internos e externos da organização que podem influenciar nos resultados desta organização e na reflexão sobre eles. (HITT; HOSKINON, 2002; CERTO; MARCONDES; CESAR, 2010; TAVARES, 2010). A ferramenta utilizada para a análise ambiental foi a Matriz SWOT (sigla oriunda dos seguintes termos em inglês, Strength, Weakness, Oportunity and Threats, que significam em português, força, fraqueza, oportunidade e ameaças, respectivamente). Assim, a Matriz SWOT viabiliza a identificação, a análise e o estabelecimento de relações entre o ambiente interno (forças e fraquezas) e o externo (oportunidades e ameaças), situando a organização analisada.

De acordo com Müller (2014, p. 43): “a partir das análises externa e interna, isoladamente, e das relações entre ambientes externo e interno, têmse elementos estruturados para a definição dos objetivos e planos estratégicos de melhorias, ou delinear as estratégias". Assim, "é da análise do ambiente que provêm as informações necessárias para que se inicie o processo de formulação de estratégias". (CERTO, MARCONDES, CESAR, 2010, p. 76).

\section{Passo 3 - Delineamento das Estratégias}

Tendo como referência a análise ambiental realizada, os encontros formativos 15, 16 e 17 foram destinados ao delineamento das estratégias (de 
sobrevivência, de manutenção, de crescimento e de desenvolimento) formuladas em termos de objetivos, desdobrados nos planos de ação. Assim, cada Unidade integrante da Diretoria de Administração traçou seus objetivos estratégicos e formulou seus planos de ação ora em curso. Também foram analisados e revistos os processos e fluxos de cada Unidade com vistas a maior celeridade na tomada de decisão e operacionalização.

Desde a conclusão do passo 3 , vem sendo realizado mensalmente um encontro, com duração de três horas, para o monitoramento (controle e avaliação) das ações projetadas. Oliveira (2013, p. 269-270) apresenta as seguintes finalidades do controle e avaliação no processo de planejamento estratégico:

\begin{abstract}
Identificar problemas, falhas e erros que se transformam em desvios do planejado, com a finalidade de corrigi-los e de evitar sua reincindência; fazer com que os resultados obtidos com a realização das operações estejam, tanto quanto possível, próximos dos resultados esperados e possibilitem o alcance dos desafios e consecução dos objetivos; verificar se as estratégias e políticas estão proporcionando os reusultados esperados, dentro das situações existentes e previstas, e proporcionar informações gerenciais periódicas, para que seja rápida a intervenção no processo.
\end{abstract}

A ferramenta gerencial adotada é o Ciclo do PDCA, cuja sigla possui o seguinte significado: P de plan - planejar; D de Do - fazer, executar; C de check - conferir, checar; A de Act - Agir. O objetivo principal do PDCA é tornar os processos de gestão mais ágeis, claros e objetivos. A sequencia cíclica das ações de planejar, executar, conferir e agir conferem a esta ferramenta gerencial uma dinamicidade e viabilizam a melhoria continua dos processos. Desta forma, o PDCA se constitui numa ferramenta amplamente adotada pelas organizações para o gerenciamento de processos e sistemas. (WERKEMA, 2013).

Nos encontros de monitoramento, já foi possivel identificar alguns desafios, tais como: a socialização e difusão do processo que está sendo realizado no âmbito da Diretoria de Administração com as demais Diretorias e respectivas Unidades que compõem a SME; b) a articulação estratégica entre as áreas administrativa e pedagógica; c) a necessidade constante de feedback, por parte da Diretoria Administrativa, reiterando os objetivos estratégicos perseguidos; d) a revisão de algumas ações para atingir os resultados almejados. Para auxiliar no processo de difusão e socialização, está em fase de estruturação a implantação da gestão à vista, compreendida como:

O processo em que os indicadores, parâmetros e critérios de avaliação, bem como a realidade atual das atividades, ficam disponíveis para acompanhamento e possível interação e intervenção do todos os envolvidos, de forma direta ou indireta, nas atividades consideradas (OLIVEIRA, 2013, p.165). 
Também é possível verificar alguns indícios de contribuições do trabalho realizado para a ação gestora no cotidiano, como, por exemplo: aumento do sentimento de pertença a um grupo; b) a busca pelo aprofundamento de subsídios teórico-metodológicos que possam contribuir para o aprimoramento das ações; c) relações interpessoais facilitando o processo comunicacional e o fluxo das informações; d) reflexão sobre a própria prática; e) comportamento proativo na busca pela resolução de problemas. Conforme salienta Zeichner (1998, p. 4):

É preciso olhar muito de perto para o caráter e para a qualidade das colaborações em pesquisas para se determinar se há realmente alguma mudança nos padrões usuais dominantes na academia. Pesquisa colaborativa é um importante caminho para superar a divisão entre acadêmicos e professores, mas não é qualquer pesquisa colaborativa que faz isso.

A projeção é de que sejam realizados encontros de monitoramento até o mês de novembro do corrente ano, sendo que, em dezembro, será posta em ação a quarta e última etapa do processo investigativo (reflexão e reorganização) da primeira fase do primeiro ciclo da pesquisa-ação colaborativa. Dessa forma, contempla-se o movimento espiralado, típico da abordagem metodológica da pesquisa-ação colaborativa, conforme explicitado a seguir.

\section{$4^{\text {a Etapa: Reflexão e reorganização }}$}

Nessa etapa ocorre o processo de reelaboração das estratégias de ação, garantindo, dessa forma, o movimento espiralado próprio da metodologia da pesquisa-ação, o qual oportuniza a continuidade do processo investigativo, seja aprofundando a temática central que originou o estudo ou abrindo novas frentes temáticas. Nela, os pesquisadores e os participantes revisitam a análise, a interpretação e a elaboração de conclusões de forma pormenorizada a partir dos registros, documentos, arquivos etc, produzidos durante as etapas anteriores. É o momento dedicado a revisar todo o processo, procurando localizar os avanços, desafios, lacunas e limitações vivenciados tanto no processo de condução da pesquisa-ação, quanto nas ações assumidas pelo coletivo.

Nesse estudo, ainda não foi possível chegar a essa etapa, estando previsto que ela ocorra ao final de 2014. Portanto, está prevista a realização de encontros cuja centralidade da discussão se dará a partir da análise, avaliação e organização dos registros produzidos pelos pesquisadores e pelos participantes do estudo. Com base nisso, serão feitas análises, interpretações e proposições para desencadear outra fase da pesquisa, cuja dinâmica traduz-se em um movimento espiralado, tal como idealizado por Lewin (2006). 


\section{CONSIDERAÇÕES FINAIS}

A gestão estratégica se tem configurado em uma necessidade também no âmbito das organizações públicas. Ou seja, na sociedade contemporânea, não é mais possível administrar tendo como único referencial a experiência constituída ao longo de uma trajetória. É fundamental que o gestor, independentemente da tipologia de organização que tenha sob sua responsabilidade, possua um conjunto de conhecimentos, de técnicas e procedimentos que viabilizem agir e tomar decisões de forma a garantir uma gestão eficiente e eficaz, cujo foco seja o alcance de determinados resultados.

O texto em pauta teve como eixo analítico discursivo o processo constitutivo do Planejamento Estratégico da Diretoria de Administração de uma Secretaria Municipal de Educação. A análise geral sobre os dados coletados no decorrer das etapas realizadas (decorrentes da análise do conteúdo de documentos, dos registros de observações dos encontros formativos no Diário de Campo e das entrevistas) sinalizam para os seguintes indícios das contribuições da pesquisa-ação colaborativa para o processo em foco: a) o aumento do sentimento de pertença a um grupo, o empoderamento e o protagonismo dos sujeitos envolvidos na contrução do planejamento; b) a reflexão sobre a própria práxis e a busca pelo aprofundamento de subsídios teórico-metodológicos que possam contribuir para o aprimoramento das ações; c) a reconstrução de conceitos e a revisão de concepções por meio da investigação-ação-formação; relações interpessoais facilitando o processo comunicacional e o fluxo das informações; d) o comportamento pró-ativo na busca pela resolução de problemas; e) a difusão da cultura de gestão estratégica nas instâncias que estruturam a SME; f) a consolidação de uma gestão pública focada em resultados; g) a corresponsabilização na efetivação do Plano de Governo 2013-2016 e do que preconizam os dispositivos nacionais sobre a educação de qualidade; h) a formação continuada daqueles que atuam na Secretaria, aprimorando suas práticas cotidianas; i) a qualificação dos serviços prestados tanto às escolas quanto à comunidade em geral, na medida em que aumenta a celeridade dos processos e práticas da área administrativa; j) a possibilidade de uma incursão aprofundada no fenômeno investigado quando se dá continuidade ao movimento espiralado, típico da pesquisa-ação.

Dentre os desafios destacam-se: a) socialização e difusão do processo que está sendo realizado no âmbito da Diretoria de Administração com as demais Diretorias e respectivas Unidades que compõe a SME; b) a articulação estratégica entre as áreas administrativa e pedagógica; c) a necessidade de feedback constantes, por parte da Diretoria Administrativa, reiterando os objetivos estratégicos perseguidos; d) a revisão de algumas ações para que se atinjam os resultados 
almejados.

Por fim, é relevante salientar os seguintes aspectos considerados essenciais para a excelência na gestão pública: a) a formação dos gestores é condição fundamental para uma gestão estratégica. Ou seja, é necessário o domínio de determinados conceitos e procedimentos específicos da área da administração, que, por vezes, os profissionais da educação ainda não possuem; b) a corresponsabilização dos gestores e demais colaboradores para que se sintam partícipes da construção de um projeto coletivo. Para tanto, é preciso assegurar espaços e tempos de escuta a esses profissionais, identificando suas concepções, perspectivas, dificuldades e ponderações; c) o empoderamento dos gestores pressupõe a construção de uma relação de confiança, de abertura e diálogo para que eles se sintam autoconfiantes e capazes de atuar na resolução de problemas cotidianos; d) a construção participativa do planejamento estratégico requer a observação e o respeito aos processos individuais e coletivos a fim de assegurar que estes estejam em consonância com a visão e missão da organização. Caso contrário, é provável que esse planejamento não se efetive e tenha os desdobramentos almejados.

\section{REFERÊNCIAS}

ANDRADE, Arnaldo R. de. Planejamento estratégico: formulação, implementação e controle. São Paulo: Atlas, 2012.

BARDIN, Laurence. Análise de conteúdo. Lisboa: Edições 70, 1988.

BOGDAN, Robert C.; BIKLEN, Sari K. Investigação qualitativa em educação. Porto: Porto, 1994.

BRASIL. Ministério do Planejamento, Orçamento e Gestão. Conselho Nacional de Secretários Estaduais de Administração. Carta de Brasília sobre Gestão Pública. Brasília: MPOG, 2008.

BRASIL. Ministério do Planejamento, Orçamento e Gestão. Secretaria do Planejamento. Programa Nacional de Gestão Pública e Desburocratização GESPÚBLICA. Documento 1. Instrumento para Avaliação da Gestão públicaCiclo 2006. Brasília: MPOG, 2006.

BRASIL, Presidência da República- Casa Civil. Decreto $\mathbf{N}^{\mathbf{0}} 5.378$ de 23 de fevereiro de 2005. Institui o Programa Nacional de Gestão Pública e Desburocratização - GESPÚBLICA - e o Comitê Gestor do Programa Nacional de Gestão Pública e Desburocratização, e dá outras providências. Brasília: Diário 
Oficial da União [da] República Federativa do Brasil, 2005.

BRASIL. Lei $\mathbf{n}^{\circ}$ 10.172, de 09 de janeiro de 2001. Aprova o Plano Nacional de Educação (PNE). Brasília: Diário Oficial da União [da] República Federativa do Brasil, 2001.

BRASIL. Lei $\mathrm{n}^{\mathbf{0}}$ 9.394, de 20 de dezembro de 1996. Estabelece as Diretrizes e Bases da Educação Nacional. Brasília: Diário Oficial da União [da] República Federativa do Brasil, 23 dez. 1996.

CARR, Wilfred. Una teoría para la educación: hacia una investigación educativa crítica. MORATA: Madrid, 1996.

CARR, Wilfred; KEMMIS, Stephen. Teoría crítica de la enseñanza: la investigación-acción en la formación del profesorado. Barcelona: Martinez Roca, 1988.

CERTO, Samuel C.; MARCONDES, Reynaldo C.; CESAR, Ana Maria R. Administração estratégica: planejamento e implantação de estratégias. 3 ed. São Paulo: Pearson Education do Brasil, 2010.

CHIAVENATO, Idalberto. Recursos humanos na empresa. Sao Paulo: Atlas, 1989.

DRUCKER, Peter F. O melhor de Peter Drucker: A administração. São Paulo: Nobel, 2009.

ELLIOTT, John. El cambio educativo desde la investigación-acción. $3^{\mathrm{a}}$. ed. Madrid: Morata, 2000.

FRANCO, Maria Amélia S. Pedagogia da Pesquisa Ação. Educação e Pesquisa, vol. 31, no 3, p. 483-502, Dezembro 2005

GIL, Antonio C. C. Método e técnicas de pesquisa social. São Paulo: Atlas, 2010.

HITT, Michael A.; HOSKINON, Robert E. Administração estratégica. São Paulo: Thompson Learning, 2002.

KEMMIS, Stephen; Mc TAGGART, Robin. Cómo planificar la investigaciónacción. Barcelona: Laertes Ediciones, 1992.

KOTLER, Philip. Administração de marketing: análise, planejamento, implementação e controle. 5.ed. São Paulo: Atlas, 1998. 
LAVILLE, Christian; DIONNE, Jean. A construção do saber: manual de metodologia de pesquisa em ciências humanas. Porto Alegre: Editora Artes Médicas Sul Ltda, 1999.

LEWIN, Kurt. La investigación-acción y los problemas de las minorías. In: SALAZAR, M. C (Org.). La investigación - acción participativa. Inicios y desarrollos. Madrid: Editorial Popular/Caracas: Editorial Laboratorio Educativo, 2006. p. 15-25.

LIBÂNEO, José C. Organização e gestão da escola - Teoria e prática. Goiânia: Editora Alternativa, 2001.

MADEIRA, José Maria P. Administração pública. $10^{\mathrm{a}}$ ed. Rio de Janeiro: Elsevier, 2008.

MAY, Tim. Pesquisa social: questões, métodos e processos. 3. ed. Porto Alegre: Artmed, 2004.

MARCONI, Marina. de A.; LAKATOS, Eva M. Técnicas de pesquisa: planejamento e execução de pesquisas, amostragens e técnicas de pesquisa, elaboração, análise e interpretação dos dados. São Paulo: Atlas, 2006.

MIRANDA, Marilia G.; RESENDE, Anita C. A. Sobre a pesquisa-ação na educação e as armadilhas do praticismo. Revista Brasileira de Educação [online], vol.11, n.33, p. 511 518, 2006.

MONCEAU, Gilles. Transformar as práticas para conhecê-las: pesquisa-ação e profissionalização docente. Educação e Pesquisa, vol. 31, n.3, p. 467-482. Dez 2005.

MÜLLER, Cláudio J. Planejamento estratégico, indicadores e processos: uma integração necessária. São Paulo: Editora Atlas S.A., 2014.

MURAD, Afonso. Gestão e Espiritualidade. São Paulo: Paulinas, 2008.

OLIVEIRA, Djalma P. R. de. Planejamento Estratégico: conceitos, metodologia, práticas. 31 a ed. São Paulo: Atlas, 2013.

PÁDUA, Elisabete M. M. Metodologia de pesquisa: Abordagem teóricoprática. Campinas: Papirus, 2011.

PAGNONCELli, Dernizo; VASCONCELlOS FILHO, Paulo. Construindo estratégias para competir no século XXI. Rio de Janeiro: Campus, 2001. 
PARO, Vitor H. Administração Escolar: Introdução Crítica. São Paulo: Cortez, 2003.

PIMENTA, Selma G. Pesquisa-ação crítico-colaborativa: construindo seu significado a partir de experiências com a formação docente. Educação e Pesquisa, vol.31, n.3, p. 521 539. 2005.

PIMENTEL, Alessandra. O método da análise documental: seu uso numa pesquisa histórica. Cadernos de Pesquisa, n.114, p.179-195, nov., 2001.

TAVARES, Mauro C. Gestão estratégica. 3. ed. São Paulo: Atlas, 2010.

WERKEMA, Cristina. Métodos PDCA e DMAIC e suas ferramentas analíticas. Rio de Janeiro: Elsevier, 2013.

ZEICHNER, Kenneth M.; DINIZ-PEREIRA, Júlio E. Pesquisa dos educadores e formação docente voltada para a transformação social. Cadernos de Pesquisa, vol. 35, n 125, p. 63 80, Maio, 2005.

ZEICHNER, Kenneth M. Para além da divisão entre professor-pesquisador e pesquisador acadêmico In: GERALDI, C. M.; FIORENTINI, D. \& PEREIRA, E. M. (orgs.) Cartografia do trabalho docente: professor(a)-pesquisador(a). Campinas: Mercado de Letras/ABL, 1998, p. 207-236.

DIRLÉIA FANFA SARMENTO é doutora em Educação pela Universidade Federal do Rio Grande do Sul com Pós-Doutoramento em Ciências da Educação pela Universidade do Algarve (Portugal). Professora do Programa de Pós-graduação em Educação do Centro Universitário La Salle de Canoas-RS. E-mail: fanfa@ unilasalle.edu.br

JARDELINO MENEGAT é doutorando em Administración de Empresas pela Universidad de La Empresa (Montevideo-Uruguai) (em fase de defesa da tese). Doutorando em Educação pelo Programa de Pós-graduação em Educação do Centro Universitário La Salle de Canoas-RS. E-mail: jardelino.menegat@lasalle.org. br

VERA LÚCIARAMIREZ é doutora em Educação pela Pontifícia Universidade Católica do Rio Grande do Sul com Pós-Doutoramento em Educação pela Universidade 
Federal Fluminense. Professora do Programa de Pós-graduação em Educação do Centro Universitário La Salle de Canoas-RS. E-mail: ramirez@unilasalle.edu.br

Recebido em agosto de 2014 Aprovado em novembro de 2014 